\title{
La hipertelevisión y el nuevo drama televisivo
}

\author{
Giancarlo Cappello \\ (Universidad de Lima)
}

Recibido: 2/3/2014

Aprobado: 3/4/2014

\begin{abstract}
Resumen: Mucho se ha escrito acerca de la gran calidad del nuevo drama al que asistimos semanalmente por televisión. Sin embargo, resulta importante comprender su desarrollo dentro de la transformación del sector audiovisual para concebirlo no como un hipo, una coincidencia o el resultado feliz de la convergencia, sino como la evolución lógica de una narrativa que se ha forjado sin perder de vista su proximidad con la audiencia.
\end{abstract}

Palabras clave: hipertelevisión / series / nuevo telespectador

\section{Hypertelevision and new TV drama}

Summary: A lot has been written about the great quality of new TV drama which we watch on television weekly. However, it is important to understand its development in the transformation of the audiovisual sector to conceive it not as an hiccups, a coincidence or the happy result of convergence, but as a logical evolution of a narrative which has been developed without losing sight of its proximity with the audience.

Key words: hypertelevision / television series / new TV viewer 
L a última década y media ha sido pródiga en contenidos de enorme calidad narrativa. La ficción televisiva, que pese a sus audacias en muchos campos siempre fue tenida como una ficción de segundo rango, hoy cosecha el elogio de actores y productores que se han volcado a trabajar en la pantalla chica admitiendo la innovación de sus propuestas. Aunque el opaco momento de la industria cinematográfica haya podido colaborar con este redireccionamiento de las luces y del interés, las propuestas más creativas del mundo audiovisual surgen de la televisión, porque son la derivación del sistema hipermediático que atraviesa el mundo contemporáneo.

En tiempos de la pantalla global, como denomina Lipovetsky a esta vida entre pantallas que convergen, se comunican, conectan entre sí y determinan nuestras relaciones con el mundo y con los demás, el relato audiovisual explota. Los grandes referentes experimentan cambios en su constitución y práctica. El cine pierde su posición hegemónica y parece una forma de expresión desfasada en relación con las pantallas electrónicas. De ahí que se esfuerce por articular de manera hiperbólica la puesta en escena, que se aferre al remake, a la adaptación, y que se interese por nuevas posibilidades de exhibición y mercadeo. A su vez, la televisión, acusada de ser verdugo del cine, vive un vértigo que evidencia su inestabilidad. Los canales de pago, los programas a la carta, la descarga de episodios, la competencia de otras pantallas en el ámbito privado (pantallas fotográficas, de información, de juego, de música) la han llevado a experimentar fusiones con internet para conservar su estirpe mediática y social.

El germen de esta transformación es tecnológico. El aura de lo digital parece permearlo todo y afectar incluso los ámbitos narrativos que sobrevivieron al boom audiovisual del siglo XX. El libro tradicional se convierte cada vez más en un $e$-book para ser leído en pantallas como el Kindle. Los espectáculos del Metropolitan Opera House se transmiten en salas de cine comercial de distintas partes del mundo. El desarrollo de teléfonos inteligentes y tablets ha abierto nuevas posibilidades de emisión y ha iniciado su propia carrera de contenidos. A tal punto llega esta eclosión que el Audit Bureau of Circulations norteamericano ha puesto en marcha un Consolidated Media Report (CMR) para medir la audiencia y la circulación de los medios en todas sus plataformas: pantallas tradicionales, papel, web, aplicaciones y redes.

Se vive un momento de intensificación basado en la atracción hacia los extremos y el paso de los límites. Se trata de una hipermodernidad que afecta de manera sincrónica y global a las tecnologías y los medios, a la economía y a la cultura. «Es el triunfo de la ambición técnica y de los derechos individuales, la realización de una so- 
ciedad liberal caracterizada por el movimiento y la fluidez» (Lipovetsky \& Charles, 2004, p. 27). De ahí que no resulte extraño señalar al público como otro factor concomitante. Las pantallas demuestran que el espectador se comporta cada vez más como un usuario y esto solo evidencia que hemos pasado de lo no conversacional de la experiencia narrativa a la búsqueda de respuestas a las acciones de la audiencia.

El ascenso de la técnica ha hecho que el público esté en condiciones de formar parte de lo que ocurre en la pantalla. La experiencia digital ha capacitado al auditorio para intervenir productos y procedimientos. Es común que el usuario programe o ajuste aplicativos de software abierto, que altere imágenes propias y ajenas gracias al Photoshop, que genere sus propios espacios de expresión vinculándose a distintas plataformas y contenidos. Los actuales dispositivos permiten la creación y difusión de conocimientos, reestructuran las relaciones interpersonales y crean nuevas necesidades y hábitos cotidianos. Entonces, ¿por qué permanecer indiferente a la pantalla?

Los antiguos parámetros de narración de historias, los espacios de consumo, la parrilla de programación, los horarios, los estrenos, los cortes comerciales, en fin, toda esa rigidez y esquematismo erosionan y se reinventan a la luz de esto que se ha denominado cultura de la convergencia. Como apunta Jenkins, se trata de una nueva relación entre las tecnologías existentes, las industrias, los mercados, los géneros y el público que altera tanto la lógica con que operan los productores como la dinámica de los consumidores para procesar la información y el entretenimiento (Jenkins, 2008). En la convergencia, el flujo de contenidos a través de múltiples plataformas mediáticas se articula gracias a la participación de los consumidores que, imbuidos en este cambio cultural, están dispuestos a generar y establecer nuevas conexiones entre contenidos dispersos.

De ahí que los relatos que consumimos en este tiempo hayan dejado de ser simplemente enunciaciones narrativas para convertirse en mundos complejos, en relaciones colaborativas, transmediáticas. La convergencia representa un cambio crucial para la narrativa audiovisual, toda vez que obliga a pensar el relato como un producto que se consolida no a partir de los efectos hipermodernos en ciertos sectores - la creación, la producción, la promoción, la distribución, el consumo-, sino en todos a la vez.

\section{La impronta digital}

Como señalara Negroponte (1995), el mundo de los átomos dio paso al mundo de los bits. De pronto el mundo construyó un correlativo digital, una réplica casi exacta de sí mismo donde puede encontrarse desde el planeta cartografiado en Google Earth hasta 
libros, revistas, diarios, videos, discos, documentos y fotografías que están en permanente ampliación y conexión, además de millones de cosas que solo pueden ser posibles a través de una computadora. Y de pronto, también, gracias al formato de los bits, la imagen numérica reemplazó al celuloide y a la imagen electrónica. Si como dice La Ferla, toda especie mediática surge del encuentro de sus distintas fuentes (2009), la imagen digital y sus posibilidades narrativas se inscriben en el proceso lógico que han seguido la electrónica, la informática y ejercicios como el videoarte y el cine experimental.

Esta transformación, primero en el cine y luego en la televisión, coincidió con una situación de crisis en Estados Unidos. La flexibilización económica de la era Reagan construyó una industria del entretenimiento cada vez más tercerizada desde el punto de vista financiero, situación que se volvió extrema veinte años después y que obligó a un consenso de uniformidad y respeto por ciertos parámetros para el espectáculo: historias que respeten la lógica de las multisalas, de la televisión de pago, «que cuesten poco (eliminando sindicatos, impuestos y deberes culturales) y que eviten, en lo posible, producciones que propongan relatos que escapen a esta dinámica de negocio» (La Ferla, 2009, pp. 179-180). Dicho de otro modo, la crisis puso en evidencia que las producciones se habían convertido en mastodontes que dependían demasiado del dinero para funcionar.
El capital para equipos era muy grande, pero iba de acuerdo con la necesidad de hacer cada vez más dinero. Invirtieron hasta tal punto, rodeándose de cálculos y metas, que se volvieron incapaces de moverse rápido, virtud que ofrece la gran oportunidad de encontrar lo diverso y cambiar junto con el público (Roman, 2001, p. 63) [la traducción es nuestra].

El mundo de los bits reflotó la industria del entretenimiento. La razón principal, sus costos. Lo digital es cada vez más barato con relación a los procesos analógicos y fotoquímicos, y conforme avanza el desarrollo técnico, los costos se reducen y sus posibilidades aumentan. Además, es una tecnología de procesos rápidos, de fácil maniobrabilidad (almacenar, grabar, copiar, distribuir, etc.) y cada vez más accesible.

Lejos de acotar sus capacidades expresivas, la conversión digital de los medios tradicionales alentó una evolución narrativa en la industria del entretenimiento, obligándola, de paso, a replantear las formas de cómo gestionaba y comercializaba sus productos. Pensemos, por ejemplo, cómo el digital ha cancelado la "pérdida de generación», es decir, la merma de calidad que se producía cada vez que se copiaba un formato analógico - a un casete, una cinta magnética, un celuloide o un video-, y que forzaba al usuario a comprar los originales para preservarlos. Cuando las copias pudieron lograrse exactas y se multiplicaron a un costo mínimo, la industria debió 
poner más de un pie en los predios digitales para no perder el paso.

En cierta forma, liberados de los grandes presupuestos que obligaban a adscribirse a las rígidas consignas de quienes aportaban el dinero, los narradores de historias recuperaron la posibilidad de enfocarse en sus propias capacidades expresivas. El triunfo de lo digital trajo consigo la independización técnica, pero también un nuevo umbral de posibilidades creativas.

El mundo digital no solo ofrece la posibilidad de trabajar al margen de las productoras tradicionales, sino también la posibilidad de escribir con estructuras diferentes a las que se exigen en el cine o en las series de televisión [...]. Los guionistas pueden probar nuevas fórmulas, por ejemplo, en relación con la duración, pues el medio digital e Internet permiten hacer piezas audiovisuales que no duren la hora y media o las dos horas de las películas, ni las duraciones estándar de las series o las sitcoms (Tubau, 2011, p. 109).

De otro lado, al ser internet la matriz articuladora donde todo transita, todo convive y todo se almacena, la lógica predominante del entorno es el hiperenlace, el vínculo que hace referencia a otro vínculo, a otro recurso, a otro documento o a un punto específico en el mismo documento, condición que afecta la dinámica del relato, sobre todo en lo que se refiere a la posibilidad de hacerlo participativo. De ahí que la experiencia hipertextual resulte fundamental para entender cómo las nuevas prácticas mediáticas —nave- gar en la web, convivir en Facebook, jugar en línea, interactuar por Twitter o Instagram - reformulan la narrativa audiovisual de este tiempo al tener que hacer frente a un espectador cada vez más acostumbrado a la participación, con una gran capacidad de adaptación a nuevos entornos de interacción.

De las grandes industrias audiovisuales, la televisión es la que mejor ha logrado ajustar y capitalizar sus recursos. Y con tal suceso que no se le reconoce más como aquella de antes. De sus foros y canteras han surgido los más estimulantes y novedosos productos narrativos del nuevo siglo $\mathrm{y}$, de alguna manera, es la industria que marca la pauta del cambio de paradigma en el modelo de gestión y negocio. Actualmente, sus contenidos se definen cada vez más a partir de las posibilidades que ofrece el soporte digital y de acuerdo con sus modos de distribución. Sus producciones son concebidas para emitirse también por canales no tradicionales, fundamentalmente el teléfono móvil e internet, y esta cualidad multipantalla, que involucra formas de consumo diferenciadas, la obliga a repensar la retórica y sintaxis de sus contenidos, ya que no es lo mismo generar un producto, por ejemplo, para el smartphone que para la «pantalla chica»: no solo por el tamaño de los aparatos, sino por la relación que se establece con ellos, por el tipo de interacción social que facilitan y por el valor y el uso que le asignamos (Guardiola, 2012). 
Esta nueva circunstancia se ha traducido en la práctica del narrowcasting (difusión selectiva), que a diferencia del broadcasting (emisión para uso público generalizado o muy amplio) permite desarrollar productos más específicos al no entrar en juego con la audiencia masiva. Esto admite, a la vez, márgenes apreciables de libertad y riesgo creativo, los mismos que pueden comprobarse en las series de televisión norteamericanas, emitidas mayormente en canales de pago o suscripción. El horizonte que se tiene por delante es insondable. Sobre todo a la luz de datos como el que indica que Netflix, la plataforma web de pago para series y películas - también gestora y productora de contenidos originales-, ya tiene más suscriptores en Estados Unidos que la cadena $\mathrm{HBO}$ en la televisión por cable ${ }^{1}$. Si bien aún está lejos de alcanzar la cobertura alrededor del globo que tiene el servicio premium de HBO, la mejora en la accesibilidad y la mayor velocidad de conexión a internet, que traerá la tecnología en los próximos años, permiten imaginar un futuro donde la televisión no será más ese aparato y esa experiencia que conocimos en el siglo $\mathrm{XX}^{2}$.

\section{Metamorfosis de la pantalla chica}

Al llegar el siglo XXI, la muerte de la televisión a manos de internet se convirtió en el centro de las especulaciones. Las tasas de audiencia disminuyeron ante el avance de nuevas pantallas: computadoras, consolas de videojuegos, teléfonos móviles. Sin embargo, así como el cine se aferró al cinemascope y la radio reformuló su estilo apelando a las posibilidades del transistor para sobrevivir, la televisión pudo someter —de momento- a las otras pantallas, convirtiéndolas en una suerte de sucursales, de vehículos de sus distintos programas gracias a la convergencia y los procesos digitales.

Esta nueva lógica multipantalla ha puesto en evidencia la necesidad de preguntarse si el término televisión sigue haciendo referencia a la industria generadora de los programas o úni-

1 Carta a los inversores de Netflix elaborada por la firma Needham \& Co., correspondiente al tercer trimestre 2013: http://files.shareholder.com/downloads/NFLX/2745605111x0x698481/ ecfe1ab4-66f5-4e23-a64a-1ca025216e5e/Q313\%20Earnings\%20Letter\%2010.21.13\%20 10.30am.pdf

2 En algún momento de la historia de esta competencia, Netflix intentó incluir series producidas por el canal de cable en su parrilla; sin embargo, la respuesta de HBO fue crear su propio servicio, HBO Go. Netflix, a su vez, decidió incursionar en la creación de series propias, ganando de paso varios Emmy con House of Cards. De momento, solo se puede acceder a HBO Go si se tiene contratado el canal con un proveedor de TV cable, lo que ha limitado la adopción de este sistema, por lo que HBO no descarta abrir el servicio. 
camente al aparato eléctrico. Lo que antes llamábamos televisión hoy se ajusta más a la idea de "contenido», y esto parece refrendarse en los nuevos modelos de negocio. Antes, el circuito de emisión indicaba, por ejemplo, que una película debía verse primero en el cine, luego pasaba al DVD, después se emitía por la televisión de pago y, finalmente, a través de la señal abierta. El diagnóstico de consenso indica que el modelo tradicional ya no es funcional para los actuales modos de consumo donde ver lo que se quiera, cuando se quiera y donde se quiera se ha convertido en algo irrenunciable. Si bien todavía se producen contenidos bajo la lógica de la paleo y neotelevisión, los tiempos que corren confirman serios dilemas en la parrilla de programación, que ya no es capaz de disponer y pautar como antes los contenidos y la vida social.

Como señala Carlos Scolari, la televisión está luchando para mantenerse en una posición central dentro de la ecología de los medios. «Es una televisión más compleja, con muchas tramas narrativas, pantallas fragmentadas y ritmo acelerado. Una televisión que, en definitiva, imita la dinámica de los medios digitales interactivos. Yo la llamo hipertelevisión» (Scolari, 2008, p. 23). Toda esta actividad ha traído consecuencias, cambios y reformulaciones en lo que se refiere al hacer televisivo, pero también en otros campos y especialidades que convergen o participan de manera tangencial. Por ejemplo, la
Nielsen Company, el gran conglomerado de medios holandés-estadounidense que provee, entre otros, servicios de información de mercado y herramientas analíticas para los negocios enfocados en el cine, la música, los libros, el entretenimiento casero y el entretenimiento interactivo, ha debido replantear sus sofisticadas herramientas estadísticas, porque la noción de consumo familiar ha erosionado. En una época donde el consumo es cada vez más atomizado, los miembros de una familia practican experiencias comunicativas particulares y esta realidad distorsiona los viejos estándares de medición.

El caso de la serie Mad Men (AMC, 2007-2014) resulta ilustrativo. Su impacto la ha llevado a ser considerada un fenómeno de culto; sin embargo, los índices convencionales le otorgan solo ocho millones de televidentes en Estados Unidos. Aun cuando la calificación Nielsen ajusta sus parámetros cada cierto tiempo, su propósito fundamental nunca ha dejado der ser medir cuántas personas están viendo un espectáculo dado en un televisor. Esta situación convencional es la que cambia a la luz de la existencia de $\mathrm{Hu}$ lu, Netflix, Apple TV, Amazon Prime, smartphone, tablets y demás. Ninguna de estas plataformas o dispositivos se reflejaban en la medición Nielsen hasta que en febrero de 2013 empezó a incluir el consumo audiovisual en streaming por internet en sus ratings.

El sistema hipermediático que rodea al medio televisivo resulta funda- 
mental para entender, en términos de Verón, el cambio que significa pasar de programar desde la oferta a programar desde el consumo. Se habla de una era post-network y de nichos (narrowcasting), más compleja, de convergencias y divergencias entre los medios masivos y los nuevos medios, que no puede conceptualizarse solamente a partir del análisis de su programación (Carlon, 2006), lo que confirmaría que el circuito audiovisual aparece hoy completamente fragmentado, donde los contenidos se emiten y son capturados por la audiencia como mejor le convenga.

Esta hipertelevisión coincidiría con una tercera fase de la televisión y la continuación de la neotelevisión, donde el prefijo hiper grafica el sobredimensionamiento descrito por Lipovetsky al hacerse patente la confluencia dentro del mismo concepto de los tres modelos de televisión: la generalista (con heterogeneidad de programas y concentración de audiencia), la temática (por cable analógico y vías digitales) y la convergente, que resulta del encuentro con internet y la telefonía móvil.

La práctica de las segundas pantallas es cada vez más extendida. En este momento, mientras lee este texto, usted puede consultar los links que se anotan, o visitar alguna página web para ampliar el detalle de las referencias. Del mismo modo, cada vez hacemos participar otras pantallas cuando se trata de ver televisión. El teléfono móvil se va convirtiendo en un complemento de la mayoría de plataformas de medios y contenidos. Los consumidores saltan entre las pantallas de la tablet y del smartphone mientras ven televisión o se internan en los videojuegos, incluso mientras se dedican al trabajo de oficina. Se trata de una lógica multitarea que apunta a potenciar la experiencia a partir de los elementos que se tienen a mano. La popular aplicación Shazam, capaz de reconocer las canciones que suenan alrededor, ahora ofrece también contenidos específicos para el usuario, mientras disfruta de su show favorito ${ }^{3}$. También está Totag', que ofrece, además de interacción entre los fans, material compartido por las emisoras o producidas por los propios seguidores.

Un informe de mayo de 2012 de JWT Intelligence, 10 ways marketers are using the second screen ${ }^{5}$, constata que las segundas pantallas se prestan para potenciar eventos en vivo, aumentar

3 Shazam for TV: Tag Shows, Get Content, Go Social: http://www.shazam.com/music/web/productfeatures.html?id=1266

4 Totag: tag along with others while you watch tv: http://tvtag.com/

510 ways marketers are using the second screen (mayo, 2012): http://www.jwtintelligence.com/ trendletters2/\#axzz2tinijbP3 
la participación de los espectadores, sincronizar el comercio electrónico con los contenidos, ofrecer a los aficionados al deporte un videojuego de su deporte favorito, además de la posibilidad de interactuar en tiempo real y entablar un intercambio vía Twitter durante un programa. Las aplicaciones diseñadas para el consumo simultáneo a través de otras pantallas y dispositivos parecen señalar el rumbo del consumo televisivo de los próximos años. La serie The Walking Dead (AMC, 2010-2013) ya tiene su propia aplicación para segunda pantalla ${ }^{6}$, con la que el espectador trasciende la experiencia de la televisión y la traslada a otros dispositivos.

En este nuevo escenario, la heterogeneidad, la espectacularidad, el sincretismo, los esfuerzos de participación e interactividad con el público y la fragmentación se acentúan. La hipertelevisión se convierte en una experiencia donde destacan «la disgregación y multiplicación de formatos a partir de la hibridación de géneros y la aparente contradicción entre fórmulas viejas y nuevas creaciones» (Gordillo, 2009, p. 15). Si la neotelevisión ya había difuminado las fronteras entre la información y la ficción, la hipertelevisión amplifica esa dinámica.

Pensemos en un programa como Cake Boss (TLC, 2009-2012) que esca- pa a las clasificaciones habituales al conjugar programa de realidad, más documental, más instructivo de cocina, más melodrama. El show cuenta las vicisitudes de una familia de pasteleros en Hoboken, Nueva Jersey. Junto a las relaciones y vicisitudes familiares del día a día (relaciones intrafamiliares, laborales, matrimonios, fallecimientos), se describe un how to do de las decoraciones de los pasteles que se preparan a propósito de algún evento especial. Lo que para la paleotelevisión habría sido un pastiche imposible, en la hipertelevisión resulta una propuesta productiva. Y, al mismo tiempo, la ficción que antes habría sido descartada para no comprometer la audiencia, para evitar la huida de auspiciadores, para no incurrir en gastos sobredimensionados ni riesgos creativos en la hipertelevisión resulta bienvenida.

En lo que concierne a la ficción, las historias reconvienen las temporalidades clásicas. La duración de una película en el cine se ve superada por historias constantes que atraviesan la oferta televisiva. Ya no es posible hallar diferencias cualitativas entre la realización cinematográfica y aquella que se hace para la televisión. Ambos territorios, tenidos hasta hace poco como creativa y artísticamente incompatibles, ahora comparten talentos, tec-

6 The Walking Dead, second screen app: http://www.theappside.com/2012/02/08/the-walkingdead-second-screen-app-gets-fans-counting-kills/ 
nología y recursos financieros. El star system fluye y se construye a través del cine, los anuncios publicitarios y los programas de televisión. Las diferencias abismales en términos de presupuestos y salarios han erosionado. Los actores de la serie Friends (NBC, 1994-2004) llegaron a cobrar un millón de dólares por capítulo, es decir, alrededor de 13 millones por temporada. $Y$ una producción como The Pacific (HBO, 2010), que narraba la intervención militar de los aliados contra el imperio de Japón, es capaz de igualar el presupuesto de cualquier superproducción de los grandes estudios. La televisión no es más el cementerio de elefantes desempleados de Hollywood, sino un atractivo medio donde Martin Scorsese decide grabar Boardwalk Empire (HBO, 2010-2014) y Frank Darabont es capaz de adaptar la serie de cómics The Walking Dead (AMC, 2010-2014).

Películas concebidas cinematográficamente inician o completan su circuito en la televisión, del mismo modo que historias originalmente televisivas se expanden a la gran pantalla. La saga Misión imposible, emitida por la CBS entre los años 1966 y 1973, se ha convertido en una franquicia de explotación por parte del cine. Igual que Hannibal, transmitida por NBC desde 2013, actualiza para la televisión el éxito de las películas alrededor del doctor y caníbal Hannibal Lecter.

«En la época hipermoderna, la película de cine no es ya el espectáculo preferido por los telespectadores, que se vuelcan con frecuencia sobre las obras de ficción televisuales» (Lipovetsky \& Serroy, 2009, p. 220). Episodios climáticos de algunas series, especialmente al inicio o final de temporada, pueden generar tanta audiencia como los grandes eventos antes insuperables: un espectáculo deportivo o un debate presidencial. A tal punto llega esta eficiencia comunicativa que la emisión de series como Prison Break (FOX, 2005-2009), Mad Men (AMC, 2007-2013), Spartacus (Starz, 2010-2012) y Dexter (Showtime, 2006-2013), por citar algunos ejemplos, significaron un nuevo impulso para sus respectivas cadenas, rescatándolas del marasmo y el desinterés que el público empezaba a manifestar.

\section{El nuevo telespectador}

Si antes era común señalar que la televisión no permitía al espectador desconectarse o trasladarse a otro mundo para vivir la experiencia del relato - dado que su atención se veía interrumpida con frecuencia por el entorno doméstico y los cortes comerciales-, si era moneda corriente indicar que la dedicación a la pantalla era flotante, inconstante, supeditada a los caprichos del zapping y a una capacidad de interiorización y compromiso limitada, el éxito del nuevo drama televisivo obliga a replantear esos viejos preceptos.

Pensemos en el décimo episodio de la tercera temporada de Breaking Bad 
(AMC, 2008-2013): «Fly», en el que Walter White se obsesiona con una mosca que se ha colado en el laboratorio. La concatenación de imágenes y sonidos a lo largo del capítulo adquiere un sentido narrativo que va más allá de proporcionar información al público o aderezar la puesta en escena: tiene de metáfora, de metamorfosis, de profecía, de delirio, de cinismo, de culpa. En Boss (Straz, 2011-2012) el alcalde de Chicago y sus colaboradores sostienen largas conversaciones acerca de personas y hechos que no han sido presentados al espectador, no hay reiteración, no existe el clásico showing, por ejemplo, a lo CSI (CBS, 2000-2014), que ante cada información nueva inserta una imagen o un sonido que permita luego rastrearla. No. En Boss, como en otras, el público asiste a un desarrollo de las acciones donde nadie parece reparar en su presencia. La cuarta pared no existe. Este nuevo y más complejo trámite exige del espectador cierto nivel de reestructuración en sus hábitos adquiridos. Y los escritores de televisión cuentan con eso.

La ficción en la hipertelevisión ha conseguido que su público siga las historias como si estuvieran viendo cine, con dedicación exclusiva y exhaustiva, con disposición al juego cognitivo (el puzzle dramático) y con un nivel de compromiso, abstracción y participación impensable para la televisión. Como dijimos antes, hemos pasado de lo no conversacional y pasivo de la experiencia narrativa a la búsqueda de respuesta a las acciones del usuario. Esto implica reconocer que estamos ante un nuevo telespectador $\mathrm{y}$, a decir de Jaques Ranciére, se trata de un «espectador emancipado» (Ranciére, 2010).

Partiendo de la experiencia teatral, Ranciére explica que la emancipación comienza cuando se cuestiona la oposición entre mirar y actuar, cuando se comprende que las evidencias que estructuran de esa manera las relaciones mismas del decir, el ver y el hacer pertenecen a la estructura de la dominación y de la sujeción. Comienza cuando se comprende que mirar es también una acción que confirma o transforma esa distribución de las posiciones. El espectador observa, selecciona, compara, interpreta, liga lo que ve con muchas otras cosas que ha visto en otros escenarios, en otros lugares, en otros soportes narrativos, en fin, en otros sintagmas de distinta índole.

[El espectador] compone su propio poema con los elementos del poema que tiene delante. Participa en la performance rehaciéndola a su manera, sustrayéndose, por ejemplo, a la energía vital que esa debería transmitir, para hacer de ella una pura imagen y asociar esa pura imagen a una historia que ha leído o soñado, vivido o inventado. De esta manera, son tanto espectadores distantes como intérpretes activos del espectáculo que se les propone (Ranciére, 2010, p. 19).

De acuerdo con esto, los espectadores ven, sienten y comprenden algo en la medida que componen su propio texto, tal y como lo hacen a su manera actores o dramaturgos, directores de 
teatro, bailarines. Este fue uno de los aspectos más notables de la serie Lost (ABC, 2004-2010), que puso en evidencia que el receptor era capaz de asumir simultáneamente varios roles: el de televidentes y el de coproductores del relato, ya que al generar blogs, foros de debate, material de circulación como infografías, wikis y demás, complementaron la experiencia narrativa y la llevaron más allá del televisor. Recordemos, por citar un caso, todo lo que supuso mostrar en la segunda temporada los tintes de un mapa que los fans se apresuraron a subir a internet después de digitalizar la imagen congelada de la pantalla. Cuando ocurrió, las conjeturas acerca del misterio de la isla y la Hanso Corporation estallaron, y esto le inyectó una vitalidad inusitada a la serie. Pronto aparecieron más mapas, más hipótesis y una serie de videos caseros colgados en YouTube que aventuraban conclusiones. Si un medio de comunicación se define a partir de la articulación entre un dispositivo tecnológico y una práctica social, Lost demostró que un nuevo hacer televisivo era posible.

La idea del espectador emancipado supone aceptar que estamos ante una instancia que tiene el poder de asociar y disociar. El poder común de los espectadores no reside en alguna forma específica de interactividad, sino en la capacidad «de traducir a su manera aquello que percibe y ligarlo a la aventura intelectual singular que los vuelve semejantes a cualquier otro, aun cuando esa aventura no se parece a ninguna otra» (Ranciére, 2010, p. 23). No hay una forma privilegiada, así como no hay un punto de partida privilegiado; todos son puntos de partida igualmente válidos, todos son cruces y nudos posibles que permiten aprender algo nuevo si rechazamos ideas como la distancia que siempre se ha impuesto entre el relato y la audiencia o cualquier distribución de roles. No se trata de transformar a los espectadores en actores o guionistas, sino en reconocer su dominio y su actividad alrededor del relato.

Ahí están los seguidores de Mad Men, que han generado más de un fan fiction donde, a modo spin-off, desarrollan personajes y situaciones que presenta la serie. The Killing (AMC, 20112014) es otro buen ejemplo: como parte de la intriga de la primera temporada, el portal de AMC desarrolló una página donde aparecían todos los personajes y donde cada quien podía elegir un sospechoso del asesinato de Rosie. Elegir uno implicaba enfrentarse a una trama diferente, como una inmensa Rayuela. O recordemos cómo los fanáticos de Lost sincronizaron los distintos niveles temporales de la historia, otorgándole nuevas lecturas. Estos casos sirven para graficar la dinámica de lo que es un relato en la hipertelevisión: ¿quién podría aventurar cuál es el fin o la totalidad de las historias si los telespectadores siguen escribiendo a través de stop motions caseros o en publicaciones ajenas al canon que luego 
los fans terminan canonizando, y así la trama crece y crece cada vez más?

Esto en el audiovisual es una novedad. El lío de los derechos y las regalías no ha permitido notar que el problema del autor es un tema que erosiona en la era digital. En el teatro, por ejemplo, esta consideración parece superada hace mucho. Para todos está claro que Sueño de una noche de verano siempre será de Shakespeare, pero que existen tantas versiones como directores, actores, escenógrafos, vestuaristas y demás participan de cada montaje de la obra. En el audiovisual, en cambio, una película como Inteligencia artificial no es de Brian Aldiss, autor del libro en que se basa, Los superjuguetes duran todo el verano; tampoco es de Carlo Collodi, de cuyo Pinocho se toman varias referencias; no se consideran las notas de Stanley Kubrick, que preparó el proyecto durante muchos años; sencillamente la película es de Steven Spielberg, el director, cuando en verdad Inteligencia artificial es de todos ellos y también de los seguidores de Blade Runner, por ejemplo, que siguen fabulando con los replicantes... Y de todos los que escriben y escribieron acerca del futuro.

Todo esto permite afirmar que en la convergencia prima una lógica que dice que la narración es un poliedro infinito. Sófocles y Eurípides modificaron e introdujeron variables en los mitos ancestrales. Virgilio usó a Homero para construir el pasado grandioso de Roma. Lo mismo hizo Mary
Shelley con Prometeo al convertirlo en el Dr. Frankenstein. Y lo mismo ocurre hoy con historias como el hundimiento del Titanic, que además del éxito de James Cameron cuenta con una larga saga de películas, novelas e historietas que pueden resultar contradictorias si las ponemos una al lado de la otra. Entonces, ¿de qué se trata todo esto? De entender que las historias son relatos perpetuos.

Pensar en un espectador emancipado entraña mucho más que la idea de integrar o compartir un proceso narrativo. Si nos detenemos en la palabra emancipación - dejar atrás un estado de minoridad-, veremos que estamos en medio de un proceso de cambio, donde las ideas de cierta modernidad y todo lo que tiene un sitio, una clase, de acuerdo con la función que le corresponde y está dotado del equipamiento sensible e intelectual que conviene a ese sitio y a esa función, se diluyen en el ámbito cultural para dar paso a prácticas que van más allá de lo que hemos entendido como una tensión entre la dominación y la liberación. La emancipación del espectador no consiste, como sugiere Ranciére, en la adquisición de nuevas capacidades, sino en la conquista de las capacidades antes negadas.

De modo que estamos ante una victoria que va más allá de la técnica y se instala en el ámbito del poder. El nuevo telespectador se hace uno, se complementa con la trama y crea una experiencia alrededor cancelando las 
distancias, los espacios, diluyendo las temporalidades y circulando e interviniendo bajo la lógica de una ética hacker. Inaugura su propia parrilla, define sus propios horarios, pautea su propio visionado. Es capaz de acceder a su serie favorita apenas unos minutos después de emitida en el país de origen, gracias a las facilidades de la tecnología y gracias a que existe otro telespectador que comparte el material a través de internet. Articulada bajo cierto catecismo fan, la comunidad de telespectadores está en condiciones de crear los subtítulos para su idioma y compartirlos en redes sociales, blogs, foros, páginas web, todo con el ánimo de intercambiar ideas, ponderar, desmenuzar la trama al detalle, aventurar hipótesis, alimentar expectativas y fundar su propia mitología. Todo esto supone, ciertamente, contar con un dominio actualizado de las herramientas que le permitan desarrollar sus capacidades e intereses, dominio siempre dinámico y versátil que le otorga los reflejos necesarios para sortear trampas y crisis, como la que ocurrió cuando Megaupload, el servicio de alojamiento masivo de archivos, fue cerrado por el FBI en 2012 por infracciones a los derechos de autor.

Este telespectador ha dotado de una vitalidad no calculada al nuevo drama televisivo. Su disposición a participar, interactuar y producir ha abierto nuevos frentes de negocio y ha convertido a estas producciones en inversiones millonarias que parecen reconocer, por primera vez en su real dimensión, que el negocio no funciona si la historia que ofrece la pantalla no colma los sentidos, las emociones y la cabeza de los consumidores de ficción.

Marcel Duchamp decía que el observador hace al cuadro. Lo mismo pasa con la televisión. Es capaz de mostrar lo mejor y lo peor del ser humano, puede radiografiar miserias y encumbrar talentos. Pero, también, nos devuelve la historia de hombres y mujeres que en este tiempo desbrozan su compleja naturaleza, su extraña idea de lo que son los sueños, las fantasías, el placer, la ambición, el dolor y el amor en sus distintas formas, en fin, las filias y fobias que componen la vida contemporánea.

\section{Referencias}

Carlón, M. (2006). De lo cinematográfico a lo televisivo: metatelevisión, lenguaje y temporalidad. Buenos Aires: La Crujía.

Gordillo, I. (2009). La hipertelevisión: géneros y formatos. Quito: QuipusCiespal.

Guardiola, I. (2012). Nuevos formatos en la ficción televisiva. En: M. Francés y G. Llorca (Coords.), La ficción audiovisual en España. Relatos, tendencias y sinergias productivas. Barcelona: Gedisa.

Jenkins, H. (2008). Convergence culture: la cultura de la convergencia de los medios de comunicación. Barcelona: Paidós. 
La Ferla, J. (2009). Cine (y) digital: aproximaciones a posibles convergencias entre el cinematógrafo y la computadora. Buenos Aires: Manantial.

Lipovetsky, G. \& Charles, S. (2004). Los tiempos hipermodernos. Barcelona: Anagrama.

Lipovetsky, G. \& Serroy, J. (2009). La pantalla global. Cultura mediática y cine en la era hipermoderna. Barcelona: Anagrama.

Negroponte, N. (1995). Ser digital. Buenos Aires: Atlantis.
Ranciére, J. (2010). El espectador emancipado. Buenos Aires: Manantial.

Roman, S. (2001). Digital Babylon. Hollywood, Indiewood y Dogma 95. Los Ángeles, CA: Lone Eagle Publishing Company.

Scolari, C. (2008). Hipermediaciones. Elementos para una teoría de la comunicación digital interactiva. Barcelona: Gedisa.

Tubau, D. (2011). El futuro de la narrativa en el mundo digital. Barcelona: Alba Editorial. 